\title{
Effective Planning and Achieving the Comprehensive Development: Al Ain University as a Model
}

\author{
Shirin S. AlOdwan \\ Mohammad Salman Alkhazaleh \\ Al-Ain University, Mohamed Bin Zayed City, \\ Abu Dhabi, United Arab Emirates
}

DOI: https://doi.org/10.36941/ajis-2022-0027

\begin{abstract}
This study aimed to identify the role of effective planning in achieving sustainable development in Al Ain University, through illustrating the relation that links the integrative theoretical framework of each of the effective planning and sustainable development. The researchers applied the descriptive survey method to investigate the non-quantitative variables and analyze them through the questionnaire into measurable quantitative variables. The study population and sample comprised all the academic leaders in Al Ain University, to whom the researchers delivered (150) copies of the questionnaire. The study relied on secondary resources such as related books, studies, magazines, and periodicals. The primary resource was constructing a questionnaire related to the study subject, and based on the theoretical framework of the study as well as the previous studies. Two statistical software were used to process the obtained data namely, SPSS and AMOS, by applying the field study on the sample to analyze the correlational and causal relationships among the study variables. The results showed that there is a medium level of strategic planning in Al Ain University as seen by its Academics and that the university achieves a medium level of sustainable development as seen by the academic leaders. The results further showed statistically significant effects at $(\alpha \leq 0.05)$ level for the dimensions of effective planning in achieving sustainable development as a whole. The correlation coefficient $(R)$ was $(0.70)$, which is a statistically significant value that indicated a statistically significant correlation between the independent and dependent variables.
\end{abstract}

Keywords: Effective planning, sustainable development

\section{Introduction}

The university is the most important available means of the governmental agencies in activating the movement of the human element and developing knowledge in the community. a package of continuous economic, social, political, ecological, and technological changes will inevitably force the university to carry out multiple functions through which it can achieve the sustainable development. The university focuses on effective planning because it is one of the modern administrative models to develop the organizations, through shifting from random administrative practices to practices based on planning, participation, excellence, and quality performance to face future difficulties and challenges. It achieves a high degree of integration among the different administrative activities at the level of the organization as a whole. It also studies the existing relations between it and the 
surrounding environment where it works and links it with all the functional units that work within the university, by developing strategies that match its general strategies. Such strategies will be the basic foundation on which the organization relies in allocating the resources, to perform its various functions to control the opportunities and threats that emerge in the organization environment (AlQahtani, Mohammad, 2015).

Planning was defined as the method based on the strategic system duly applied in the organization, which is built on an in-depth study of the opportunities and the threats that exist in the external environment of the organization. The strengths and weaknesses in the internal environment should be taken into account to carry out the operations in the proper way. Thereafter, to evaluate and improve the institutional performance and face the challenges and crises to obtain the desired results (Ja'afar, 2017).

Shweideh (2015) defines planning as a pool of steps and procedures that work toward understanding the surrounding environment and finding radical and effective solutions to realize the required, active change. Abdel Mawla (2017) defines it as one of the important leading positions in the general management, which the administrative leadership is burdened to raise as a fundamental function of the higher management exclusively.

Effective planning is one of the important administrative issues that met wide attention in management science. It is the only tool of the institution that enables it to face the accelerating changes in both its internal and external environments. It also represents the base through which its vision, mission, objectives, and available abilities are determined. These objectives are translated into plans and programs at all the levels inside it and are deemed the basis of any future strategic plan (Sha'ath, 2015). Further, effective planning is the type of planning that is based on a realistic and deep understanding of what is going around in both the internal and external environments, and on an attempt to understand their strengths and weaknesses. It is further based on monitoring the opportunities and risks that increase the ability to foresee the future, as well as preparing for this future by defining and choosing several alternatives (strategies). These alternatives are applied in the organization to achieve its objectives, which can affect the organization environment toward providing suitable conditions that help to facilitate goal achievement (Saleh, 2013; Mraizeeq, 2011).

Arab countries began heading toward comprehensive development and sustainable development through effective planning, due to its significance in raising the educational institution's performance in the present and future, if applied in a good manner. Adopting effective planning assists in achieving various benefits, such as: setting a roadmap of the university; contributing to the increase of its ability to face the intensely local and foreign competition; granting it the ability to possess a continuous competitive advantage; enabling the university the effective use of its resources; and achieving sustainable requirements (Assaf, 2015; Al-Ghzawi and Al-Sharafat, 2014; \& Saleh, 2011).

Since sustainable development is one of the major objectives that the governments seek to raise the life level in all its aspects (political, social, military, administrative, and ecological), it can only be realized through the duality of the planning and development as a base of the proper developmental work. The universities set many plans according to the comprehensive national policies managed and supervised by them to develop them and make them reach the entrepreneurship position (Bin Omar, 2015; Pollard, 2016).

Universities have a unique position in achieving sustainable development objectives, as they are the main concerned institutions at the universal level to produce scientific, technological, and social knowledge. They spread out this knowledge to the generations to come, and analyze the public policies outside the political framework. Universities are also the places where teachers are trained; they qualify the engineers, scientists, and advanced technology companies, diagnose the challenges that face their communities, and work to overcome them (D'ais, 2020).

Achieving change and development at any level, institution or state is faced with crises that hinder, limit, or disrupt the targeted sustainable development process, anywhere, anytime. In other words, crisis occurrence is quite natural, and the university that follows a systematic plan is the effective university that achieves sustainable development. The university that looks after its 
activities and manages them by effective and studied planning will have many earnings that are related to the objectives of its workers. Moreover, it will provide the ability to interact with its environment; achieve advanced performance because it precisely exploits its resources; allocate these resources the way that helps it invest the opportunities; enhance the available strengths, and remove the risks and weaknesses.

\subsection{Previous Studies}

The researchers reviewed several Arabic and foreign studies which were a source of inspiration in conducting this research.

Al-Oqaili, Majd (2019) conducted a study titled "Strategic planning is an important factor in the comprehensive development." It aimed at identifying the effect of systematic strategic planning in achieving comprehensive development in educational institutions. The researcher applied the qualitative method, and the most important results were that the proper, systematic, codified planning leads to realizing sustainable development in all economic, cultural, social, and cognitive areas. The study emphasized that proper planning can foresee the future and set a successful plan and vision. The study further found a relationship between planning and comprehensive development.

Al-Kardas (2018) conducted a study that aimed at identifying the desired role of the Palestinian universities in strengthening sustainable development. The researcher applied the desk descriptive approach to identify the literature related to the universities and sustainable development. The study showed that the aspired level of the Palestinian universities in strengthening sustainable development was high. The study further showed that changing the role of the Palestinian universities through technological education, and education based on innovation and creativity for employment and focus on the principle of creating job opportunities, contributed to strengthening sustainable development.

In the same vein, Ja'afar (2017) conducted a study aimed at identifying the elements of effective strategic planning, and the factors that should be taken care of by leaders of the institutions. The study population comprised 850 participants, and the results showed that strategic planning in educational institutions contributes to a decrease in the probable problems. In addition, the study showed that low participation of the employees in strategic planning is an obstacle in problemsolving, and reveals the strengths and weaknesses in the institution. Also Al-Ali (2016) conducted a study titled "Role of the strategic planning in achieving the sustainable development in $\mathrm{Al}$ al-Bayt University, which aimed at defining the role of strategic planning in achieving sustainable development in $\mathrm{Al}$ al-Bayt University. The study sample comprised 560 academics and administrators and applied the analytical descriptive method. The study concluded that there is a medium level of strategic planning, and there are obstacles to the strategic planning in the development management, which prevented the university from reaching comprehensive development.

Nusair (2015) carried out a study titled "Role of the university education in achieving the sustainable development as seen by the students". It aimed at revealing the role of university education in achieving sustainable development from the views of Jarash University students. The researcher constructed a five-point grading questionnaire and reviewed the theoretical literature and previous studies. The study was applied to a sample of (253) students who were chosen randomly. The results showed that university education achieved sustainable development at a medium level in the fields of community service and students, and at the administrative level.

Al-Zo'bi (2014) conducted a study titled "Degree of strategic planning practice in the Jordanian universities and its relationship with development." This study identified the practice degree of strategic planning in both the public and private sectors universities and its relationship with development. The study population consisted of (224) academic leaders and the sample comprised (173) academic leaders in Jordanian universities. The results showed that the practice degree of strategic planning in the Jordanian universities was high. Meanwhile, the reality of the management 
and development was medium as seen by the academic leaders.

In the light of the above, the study made some recommendations including work toward developing positive attitudes with the rectors and workers of the public and private sectors universities to adopt the strategic planning culture; and inclusion of the administrators in practicing the recruitment, selection, and employment of the human resources managers.

Study of Smith (2013) aimed at identifying the strategic planning in the educational institutions in Britain, and crisis management to achieve sustainable development. The study applied the documentary analytical method to analyze its documents, compare the works and observe the performance of the administrators in these institutions. The results showed that the absence of setting realistic plans for work with defined objectives led to the failure of the planning processes that the British universities carry out until now.

The abovementioned studies addressed the issue of strategic planning and its relations with sustainable development. Most of these studies focused on it and linked it with many variables. By contrast, our study focused on strategic planning in achieving sustainable development through the academic leaders at Al Ain University.

\subsection{The Study Problem}

The study problem revolved around the following questions:

1. What is the role of effective planning in the university as seen by the academic leaders in $\mathrm{Al}$ Ain University?

2. What is the role of the university in achieving sustainable development as seen by the academic leaders in $\mathrm{Al}$ Ain University?

3. Is there a role at $(\alpha>0.05)$ statistical significance level in achieving sustainable development as seen by the academic leaders in the University?

\subsection{Significance of the Study}

The significance of this study stems from addressing one of the relatively new administrative and developmental issues, which is strategic planning and its relations with sustainable development. This topic is nowadays deemed of great and direct importance in terms of the future of the educational institutions. This is due to the complexity of the external environment and the multiple factors and variables that affect work performance and expose the future objectives to many risks and threats. Therefore, the study is of increased importance, especially in the multiple technological, economic, and political conditions and changes that the universities witness and focus on. Such changes require the study of strategic planning and sustainable development to know the relationship between them, benefit the positive scientific results, and reflect them on the practical reality. Its significance further stems from investigating the role of practicing effective planning in the universities and reflecting it on the administrative process performance, which includes preparing the socioeconomic plans that are based on policies and programs through which the developmental projects are implemented according to the available financial resources. In addition, the significance of the study arises from identifying the way in dealing with the developmental activities, in terms of the strategic thought, environmental analysis, formation of the strategic plans, implementing, follow-up, and evaluating them by the academic leaders.

\subsection{Procedural Definitions}

Effective planning: is an activity applied by all the academic leaders in the university in managing the university affairs, through intellectual plans that focus on a delicate thought, and then transforming these plans into actual, systematic, and proper plans.

Sustainable development is the university's ability to achieve the objectives of this 
development at the international level, by producing scientific, technological, and social knowledge, promulgating such knowledge among the forthcoming generations, and analyzing the general policies outside the political framework.

\subsection{Limits of the Study}

Human limits: the current study is limited to the academic leaders at Al Ain University.

Time limits: the study is applied during the first semester of the university academic year 2020/2021 AD.

\subsection{Method}

The survey descriptive method was adopted to monitor the nature of the phenomenon subject matter of the study, and extract the results through applying a field study on the academic leaders in the various colleges and departments of the university.

\subsection{Population and Sample}

The study populations consisted of all the academic leaders in Al Ain University (Rector, rector deputies, deans of the faculties, and heads of sections).

The sample comprised 150 participants of the academic leaders in the university.

\subsection{The Study Instrument}

The researchers used the questionnaire as the data collection tool, which measures the role of the university in using strategic planning to achieve sustainable development. The questionnaire has two variables: the first is the effective planning that consists of five dimensions (participation, strategy, planning method, infrastructure, and the financial and human resources), with (35) items allocated to it. The second variable is sustainable development, which also includs five dimensions (development requirements, development method, economic dimension, social dimension, and the environmental dimension) with (...) items allocated to it.

\subsection{Validity of the Instrument}

To verify the validity of the instrument, it was subjected to the apparent validity test, by presenting to a pool of judges with experience and specialization in the study topic $(n=9)$, to identify the availability extent of the following aspects of the instrument:

- Language accuracy of wording the questionnaire items.

- The extent of the questionnaire suitability and inclusion of all the dimensions that measure the variables.

- The degree of how far the items are suitable to the dimension they belong to.

To analyze the data and test the study questions, Likert five-point scale was adopted to respond to the questions as per the following degrees: (1) degree for strongly disagree, (2) degrees for disagreeing, (3) degrees for moderately agree, (4) degrees for agreeing, and (5) degrees for strongly agree. After making the equation for the tool and converting it to 3 levels, the following criterion was adopted:

From 1 to less than 2.33, little approval

From 2.33 to less than 3.66, the approval is average

As for the high approval, it started from 3.66 to 5 


\subsection{The Confirmatory Factorial Analysis}

The researchers utilized AMOS software $\left(22^{\text {nd }} \mathrm{Ed}\right)$ to obtain the confirmatory factorial validity of the items of independent, dependent, intermediary, and amended variables. In this concern, it is established that the quality of the collected data is very important for verification, as it reflects the reliance degree on the study items, and documenting it by the produced results. This software included many indicators to judge the quality of the model data. The researchers relied on four indicators that are followed by most of the studies. Chi-square test and test significance level, which are the most important and powerful scientific tests that measure the model quality. Yet, this test is criticized for its sensitivity of two points: the first is the freedom degrees that are related to many variables, and the second is the size of the sample, as the significance value is affected by these points to a wide extent. The other indicator is the goodness of fit index (GFI), which is a general statistical index and comes next to the Chi-square test in terms of importance. Its value ranges between o and 1 , so that if it is equal to the integer one, then it will be indicative of the full fitness, which is an ideal condition. Studies further depend on CFI (comparative fit index), which value is between o1 and 1, so that if the value is integer one, it indicates a perfect fitness.

As for the last index, the square root of the mean of the squares of the evaluation errors (RMSEA), depends on the amount of the square of the differences between the two models, so that the lower the value of this index, the better the quality is. The best is when these errors equal zero, which is the ideal state that indicates a complete fitness. The above details indicate that the judgment indicators of the model quality are multiple, and the researchers should not rely on one certain indicator. Thus, reading these indexes, interrelating them, and reliance on two of them (at least) to judge the model data, may help the researchers to take the right decision of judgment.

Table 1: Results of the confirmatory factorial validity of the items of the independent variable dimensions of the effective planning (Standard saturations of the items on their dimensions)

\begin{tabular}{|c|c|c|c|c|c|}
\hline Item Code & $\begin{array}{c}\text { Planning } \\
\text { Method }\end{array}$ & $\begin{array}{c}\text { Human } \\
\text { Financial Resources }\end{array}$ & Strategy & $\begin{array}{l}\text { Participation } \\
\text { and Training }\end{array}$ & Infrastructure \\
\hline X1_1 & .814 & & & & \\
\hline $\mathrm{X} 1 \_2$ & .632 & & & & \\
\hline $\mathrm{X}_{1} \_3$ & .693 & & & & \\
\hline $\mathrm{X}_{2} \_1$ & & .724 & & & \\
\hline $\mathrm{X} 2 \_2$ & & .762 & & & \\
\hline $\mathrm{X}_{3 \_1}$ & & & .752 & & \\
\hline $\mathrm{X}_{3 \_2}$ & & & .712 & & \\
\hline $\mathrm{X}_{3-3}$ & & & .669 & & \\
\hline $\mathrm{X}_{4 \_1}$ & & & & .705 & \\
\hline $\mathrm{X}_{4 \_2}$ & & & & .611 & \\
\hline $\mathrm{X}_{4-3}$ & & & & .623 & \\
\hline $\mathrm{X}_{5 \_1}$ & & & & & .632 \\
\hline $\mathrm{X}_{5 \_2}$ & & & & & .587 \\
\hline
\end{tabular}

Table 1 shows the values of the saturation of each item on the dimension (factor) it belongs to, which is termed "convergent validity", which is the value of the standard saturations between every item and the dimensions that include it. The saturation value is acceptable if it interprets at least $50 \%$ of the variance between this item and the dimension it belongs to, where the total standard variance equals one "integer", (although some studies accept it at $40 \%$ as a minimum). Therefore, $50 \%$ of variance as a minimum is accepted for saturations values. 
Table 2: Results of the confirmatory factorial validity of the items of the dependent variable dimensions of the sustainable development (Standard saturations of the items on their dimensions)

\begin{tabular}{|c|c|c|c|c|c|}
\hline $\begin{array}{l}\text { Item } \\
\text { Code }\end{array}$ & $\begin{array}{l}\text { Planning } \\
\text { Method }\end{array}$ & $\begin{array}{l}\text { Development } \\
\text { Requirements }\end{array}$ & $\begin{array}{c}\text { Economic } \\
\text { Dimension }\end{array}$ & $\begin{array}{c}\text { Social } \\
\text { Dimension }\end{array}$ & $\begin{array}{l}\text { Environmental } \\
\text { Dimension }\end{array}$ \\
\hline Y1_1 & 0.488 & & & & \\
\hline Y1_2 & 0.844 & & & & \\
\hline $\mathrm{Y}_{1} \_3$ & 0.787 & & & & \\
\hline Y2_1 & & 0.612 & & & \\
\hline $\mathrm{Y} 2 \_2$ & & 0.769 & & & \\
\hline $\mathrm{Y}_{2} \_3$ & & 0.749 & & & \\
\hline$Y_{3 \_1}$ & & & 0.622 & & \\
\hline $\mathrm{Y}_{3 \_2}$ & & & 0.690 & & \\
\hline $\mathrm{Y}_{4 \_1}$ & & & & 0.643 & \\
\hline $\mathrm{Y}_{4 \_2}$ & & & & 0.624 & \\
\hline$Y_{5 \_1}$ & & & & & 0.553 \\
\hline $\mathrm{Y}_{5 \_2}$ & & & & & 0.600 \\
\hline $\mathrm{Y}_{5-3}$ & & & & & 0.702 \\
\hline
\end{tabular}

Table 2 shows the values of the saturation of each item on the dimension (factor) it belongs to, which is termed "convergent validity", which is the value of the standard saturations between every item and the dimensions that include it. The saturation value is acceptable if it interprets at least 50\% of the variance between this item and the dimension it belongs to, as the total standard variance equals one "integer", (although some studies accept it at $40 \%$ as a minimum). Therefore, $50 \%$ of variance as a minimum is acceptable for the saturation values.

Table 3: Results of the instrument reliability by Cronbach Alpha and results of AVE and Composite Reliability

\begin{tabular}{|l|c|c|c|}
\hline Variable & AVE & Composite Reliability & Cronbach Alpha \\
\hline Independent Variable (Strategic Planning) & 50.29 & .947 & .922 \\
\hline Dependent Variable (Sustainable Development) & 50.14 & .931 & .877 \\
\hline
\end{tabular}

Table 3 shows the value of AVE (average variance extracted) through the saturations of the items that represent every basic variable in the study, which indicate the rates of the common variance of the factor among the items that compose it. Higher values reflect higher variance validity of the dimension of the items. Knowing that there is no certain definite point at which AVE could be deemed a reference through the items. Even though, the higher than $50 \%$ the value is, the more it indicates preference and higher variance validity. The results illustrated in the Table show that the values ranged between 29 and 50 in the independent variable and (11-60) in the intermediary variable. As for the values of the composite reliability that is measured by the standard saturation resulting from the confirmatory factorial analysis, which reflects the composite reliability of the items of every sub-dimension that is a component of the basic variable in the study, they were high values. The lowest was in the dependent variable (o.931), which is a high value (the highest value this reliability can reach is integer one). This reliability is distinguished from the traditional internal consistency in that it takes into account the values of the squares of the error remainders, which are not addressed in the traditional manner, which means an increase in the accuracy of estimating the reliability of every dimension.

Based on reviewing the reliability values by Cronbach Alfa method, which depends on the ratio of the total items variance to the total degree variance after correcting them by a coefficient based on the number of items, we find that the lowest reliability value obtained in the dependent variable was (o.877), a value that reflects a high-reliability degree in this way. Thus, based on these results, we can 
tell that the study variables have high-reliability values and could be used in this study.

\section{Results and Discussion}

Results of the first question and their interpretation: What is the role of effective planning in the university as seen by the academic leaders in Al Ain University? To identify the level of effective planning, the researchers obtained the means and standard deviations of the sample participants' evaluations about the independent variable dimensions of the effective planning, and the domain as a whole, as illustrated in Table (4).

Table 4: Means and standard deviations of the independent variable items (effective planning) in the university as seen by its workers.

\begin{tabular}{|c|l|c|c|c|c|c|}
\hline No. & \multicolumn{1}{|c|}{ Dimensions } & M & SD & Relative Significance & Level & Rank \\
\hline $\mathbf{1}$ & Participation and Training & 3.66 & 0.57 & 73.3 & High & 4 \\
\hline 2 & Strategy & 3.63 & 0.60 & 72.7 & Medium & 3 \\
\hline 3 & Planning Method & 3.49 & 0.53 & 69.8 & Medium & 1 \\
\hline 4 & Infrastructure & 3.38 & 0.56 & 67.5 & Medium & 5 \\
\hline 5 & Financial Human Resources & 2.99 & 0.75 & 59.7 & Medium & 2 \\
\hline \multicolumn{2}{|c|}{ Planning Domain as a Whole } & 3.47 & 0.40 & 69.4 & Medium & \\
\hline
\end{tabular}

Table 4 shows that the planning level was evaluated at a medium degree according to the rating scale adopted by the researchers. The mean of the total degree of the strategic planning dimensions was (3.47) which represents (69.4\%) relative significance. The means ranged between 2.99 and 3.66. Participation and training dimension ranked first with (3.66) mean and (73.3\%) relative significance; strategy dimension ranked second with (3.63) $\mathrm{M}$ and (72.7\%) relative significance; planning method ranked third with (3.49) $\mathrm{M}$ and (69.8\%) relative significance; infrastructure dimension ranked fourth with (3.38) $\mathrm{M}$ and (67.5\%) relative significance, and the financial human resources dimension ranked fifth and last with (2.99) $\mathrm{M}$ and (50.7\%) relative significance.

Generally, the results showed a medium level of effective planning in the university. The researchers ascribe this to the university attempts, through effective planning, to direct the administrators and academics and increase their interest in the topics that have priority. This is done by providing suitable information that enables them to make the best decisions and focus the available resources in the university on the necessary and important things. Effective planning contributes to defining the university objectives more realistically, improves and contributes to the improvement of the abilities of the human resources.

This result could be further explained by the university seeks, through effective planning, to analyze the factors of its internal environment comprehensively and systematically. This will help to define the strengths and weaknesses in the university, which contribute to the increase of its efficiency and ability to take strategic decisions accordingly and choose the available alternatives that match the objectives and aspirations of the university. These results are in line with the study of AlAli (2016) which endorsed the existence of a medium level of strategic planning. On the other hand, it is not in line with the study of Al-Zo'bi (2014), which emphasized that the practice degree of the strategic planning in the Jordanian universities was high, and Ja'afar (2017) showed that strategic planning contributes to decreasing the potential problems.

To identify the level of effective planning with more details, the researchers extracted the means and standard deviations of the items of each dimension of the effective planning domain separately, as shown in Table (5). 
Table 5: Means and standard deviations of the items of each of the independent variable dimensions (strategic planning) in the university, as seen by its academics.

\begin{tabular}{|c|c|c|c|c|c|c|}
\hline No. & Item & $\mathbf{M}$ & SD & $\begin{array}{c}\text { Relative } \\
\text { Significance } \\
\end{array}$ & Level & Rank \\
\hline 1 & The university encourages using effective planning. & 3.47 & 0.74 & $69 \cdot 3$ & Medium & 3 \\
\hline 2 & The university is persuaded in the importance of using effective planning. & 3.33 & 0.73 & 66.7 & Medium & 4 \\
\hline 3 & $\begin{array}{l}\text { There is understanding and ability with the university to use effective } \\
\text { planning. }\end{array}$ & 3.50 & 0.66 & 69.9 & Medium & 2 \\
\hline 4 & The university uses the strategic thought method. & 3.66 & 0.77 & 73.2 & High & 1 \\
\hline \multicolumn{2}{|r|}{ The planning method dimensions as a whole } & 3.49 & 0.53 & 69.8 & Medium & 3 \\
\hline 5 & $\begin{array}{l}\text { The university provides the required financial resources for effective } \\
\text { planning. }\end{array}$ & 2.94 & 0.87 & 58.7 & Medium & 2 \\
\hline 6 & $\begin{array}{l}\text { The university provides the required human resources for effective } \\
\text { planning. }\end{array}$ & 3.04 & 0.86 & 60.8 & Medium & 1 \\
\hline \multicolumn{2}{|r|}{ Human resources dimension as a whole. } & 2.99 & 0.75 & $95 \cdot 7$ & Medium & 5 \\
\hline 7 & $\begin{array}{l}\text { The university analyzes the internal and external environments to identify } \\
\text { its strengths and weaknesses. }\end{array}$ & $3 \cdot 31$ & 0.67 & 66.2 & Medium & 3 \\
\hline 8 & The university has a clear and understandable vision of its mission. & 3.71 & 0.98 & 74.2 & High & 2 \\
\hline 9 & $\begin{array}{l}\text { The university chooses the proper strategy to achieve its objectives, } \\
\text { vision, and mission. }\end{array}$ & 3.88 & 0.76 & 77.6 & High & 1 \\
\hline \multicolumn{2}{|r|}{ Strategy dimension as a whole } & 3.63 & 0.60 & 72.7 & Medium & 2 \\
\hline 10 & $\begin{array}{l}\text { The university shares the academic leaders in the colleges in preparing } \\
\text { the work objectives and choosing the proper strategy to implement them. }\end{array}$ & 3.79 & 0.75 & 75.8 & High & 1 \\
\hline 11 & $\begin{array}{l}\text { The university develops the efficiency of the workers continuously in a } \\
\text { manner that achieves the implementation of the strategic plan and its } \\
\text { objectives. }\end{array}$ & 3.75 & 0.73 & 75.1 & high & 2 \\
\hline 12 & $\begin{array}{l}\text { The university provides efficient administrative skills to implement its } \\
\text { strategy at the occupational level. }\end{array}$ & 3.45 & 0.64 & 68.9 & Medium & 3 \\
\hline \multicolumn{2}{|r|}{ Participation and training as a whole } & 3.66 & 0.57 & 73.3 & High & 1 \\
\hline 13 & $\begin{array}{l}\text { The university provides the material and technical abilities for the } \\
\text { effective planning process. }\end{array}$ & 3.84 & 0.81 & 76.7 & High & 1 \\
\hline 14 & $\begin{array}{l}\text { The university provides data and information systems to practice effective } \\
\text { planning and to be updated continuously. }\end{array}$ & 2.92 & 0.76 & 58.4 & Medium & 2 \\
\hline \multicolumn{2}{|r|}{ Infrastructure dimension as a whole } & 3.38 & 0.56 & 67.5 & Medium & 4 \\
\hline
\end{tabular}

Table 5 shows the following:

1. The means of the sample participants' evaluations on the items of planning method dimension ranged between 3.33 and 3.66. Item (4) providing "The university uses the strategic thought method", ranked first; and item (2) providing "The university is persuaded in the importance of using the effective planning" ranked last.

2. The means of the sample participants' evaluations on the items of financial and human resources dimension ranged between 2.94 and 3.04. Item (6) providing "The university provides the human resources required for the effective planning", ranked first' and item (5) providing "The university provides the financial resources required for the effective planning", ranked last.

3. The means of the sample participants' evaluations on the items of strategy dimension ranged between 3.31 and 3.88. Item (9) providing "The university chooses the proper strategy to achieve its objectives, vision, and mission", ranked first' and item (7) providing "The university analyzes the internal and external environments to identify its strengths and weaknesses", ranked last.

4. The means of the sample participants' evaluations on the items of participation and training dimension ranged between 3.45 and 3.79. Item (10) providing "The university shares the academic leaders in colleges in preparing the work objectives and choosing the proper strategy to implement them", ranked first' and item (12) providing "The university provides efficient administrative skills to implement its strategy at the occupational level", ranked last.

5. The means of the sample participants' evaluations on the items of infrastructure dimension 
ranged between 2.92 and 3.84. Item (13) providing "The university provides the material and technical abilities for the effective planning process", ranked first' and item (14) providing "The university provides data and information system to practice the effective planning and to be updated continuously", ranked last.

\subsection{Results of the second question and its interpretation}

What is the role of the university in achieving sustainable development as seen by the academic leaders in Al Ain University? To identify the level of sustainable development, the researchers extracted the means and standard deviations of the sample participants' estimations about sustainable development and the domain as a whole, as illustrated in Table (6).

Table 6: Means and standard deviations of the sustainable development in the university as seen by its academic leaders

\begin{tabular}{|c|l|c|c|c|c|c|}
\hline No. & Domains & M & SD & Relative Sign. & Level & Rank \\
\hline 1 & Development requirements & 3.74 & 0.63 & 74.8 & High & 2 \\
\hline 2 & Development method & 3.71 & 0.73 & 74.2 & High & 1 \\
\hline 3 & Economic dimension & 3.45 & 0.63 & 69.0 & Medium & 3 \\
\hline 4 & Social dimension & 3.31 & 0.71 & 66.2 & Medium & 4 \\
\hline 5 & Environmental dimension & 3.02 & 0.67 & 60.4 & Medium & 5 \\
\hline \multicolumn{2}{|l}{ The sustainable development domain as a whole } & 3.46 & 0.49 & 69.2 & medium & \\
\hline
\end{tabular}

Table 6 indicates that the sustainable development level was estimated at a medium degree as per the rating scale that the researchers adopted. The mean of the total degree of sustainable development amounted to (3.46) with (69.2\%) relative significance, and the means ranged between 3.02 and 3.74. The development requirements dimension ranked first with (3.74) mean and (74.8\%) relative significance; the development method came second with (3.71) mean and $(74.2 \%)$ relative significance; the economic dimension was third with (3.45) mean and (69.0\%) relative significance; the social dimensions came fourth with $(3.31)$ mean and $(66.2 \%)$ relative significance, and the environmental dimension came fifth and last with (3.02) mean and (60.4\%) relative significance.

In general, the results of the instrument for sustainable development as a whole were at a medium level. There is a clear understanding of the sustainable development concept in the university. Also there is work to achieve sustainable economic, human, social, and environmental development, and invest the results of the scientific research in addressing the economic, social, and environmental issues, and transforming the knowledge into wealth. The reason is that the nature of the university's work, objectives, and mission is directly related to sustainable development, which in turn requires it to play a pioneering role in sustainable development. In addition, the importance of sustainable development in strengthening the intellectual image of the university in the local community contributes to achieving great benefits to it. The researchers attribute this to the excellence in applying sustainable development in the university which requires the application of a number of programs and policies to ensure sustainable development standards. In addition, it requires holding conferences and seminars to activate these standards at the level of the university. This result is in line with those of Nusair's study (2015) that asserted that university education realizes sustainable development at a medium degree. On the other hand, our study is not in line with that of Al-Kardees's (2018) results which emphasized that the aspired level of the Palestinian universities in strengthening sustainable development is high.

To identify the level of sustainable development in more detail, the researchers extracted the means and standard deviations of the items of each dimension of the sustainable development domain separately, as shown in Table (7). 
Table 7: Means and standard deviations of the items of every dimension of the dependent variable (sustainable development) in the university as viewed by its academics.

\begin{tabular}{|c|c|c|c|c|c|c|}
\hline No. & Item & $\mathbf{M}$ & SD & $\begin{array}{l}\text { Relative } \\
\text { Sign. }\end{array}$ & Level & Rank \\
\hline 1 & $\begin{array}{l}\text { The university has a clear understanding of the sustainable } \\
\text { development concept. }\end{array}$ & 3.63 & 0.87 & 72.6 & Medium & 1 \\
\hline 2 & $\begin{array}{l}\text { The university has a conviction of the sustainable development } \\
\text { importance. }\end{array}$ & 3.60 & 0.83 & 72.1 & Medium & 3 \\
\hline 3 & $\begin{array}{l}\text { The university applies the strategic management method to } \\
\text { achieve sustainable development. }\end{array}$ & 3.90 & 0.83 & 78.0 & High & 1 \\
\hline \multicolumn{2}{|r|}{ Development method as a whole } & 3.71 & 0.73 & 74.2 & High & 2 \\
\hline 4 & $\begin{array}{l}\text { The university provides the required financial amounts to } \\
\text { achieve sustainable development. }\end{array}$ & 3.89 & 0.79 & $77 \cdot 7$ & High & 2 \\
\hline 5 & $\begin{array}{l}\text { The university provides the required human cadres to achieve } \\
\text { sustainable development. }\end{array}$ & 3.91 & 0.87 & 78.1 & High & 1 \\
\hline 6 & $\begin{array}{l}\text { The ministry provides the required infrastructure to achieve } \\
\text { sustainable development. }\end{array}$ & 3.44 & 0.66 & 68.8 & Medium & 3 \\
\hline \multicolumn{2}{|r|}{\begin{tabular}{|l} 
The development requirements as a whole. \\
\end{tabular}} & $3 \cdot 74$ & 0.63 & 74.8 & High & \\
\hline 7 & $\begin{array}{l}\text { The university works on raising the economic growth level to } \\
\text { improve the living level of the individuals. }\end{array}$ & $3 \cdot 39$ & 0.68 & 67.8 & Medium & 2 \\
\hline 8 & $\begin{array}{l}\text { The university works on reducing the poverty and } \\
\text { unemployment levels among the community members. }\end{array}$ & $3 \cdot 52$ & 0.85 & 70.3 & Medium & 1 \\
\hline \multicolumn{2}{|r|}{ The economic dimension as a whole. } & 3.45 & 0.63 & 69.0 & Medium & 3 \\
\hline 9 & $\begin{array}{l}\text { The university works toward achieving human development and } \\
\text { building the knowledge labor of the community members. }\end{array}$ & $3 \cdot 53$ & 0.86 & 70.7 & Medium & 1 \\
\hline 10 & $\begin{array}{l}\text { The university seeks to increase and strengthen the role of civil } \\
\text { organizations in achieving sustainable development. }\end{array}$ & 3.09 & 0.86 & 61.9 & Medium & 2 \\
\hline \multicolumn{2}{|r|}{ The social dimension as a whole } & 3.31 & 0.71 & 66.2 & Medium & 4 \\
\hline 11 & $\begin{array}{l}\text { The university depends on employing the research results to } \\
\text { address the environmental issues. }\end{array}$ & 3.08 & 0.86 & 61.5 & Medium & 1 \\
\hline 12 & $\begin{array}{l}\text { The university seeks to activate the human rights laws that are } \\
\text { related to environmental issues. }\end{array}$ & 3.00 & 0.83 & 60.0 & Medium & 2 \\
\hline 13 & $\begin{array}{l}\text { The university aims at achieving balanced environmental } \\
\text { development among all the colleges. }\end{array}$ & 2.97 & 0.74 & $59 \cdot 5$ & Medium & 3 \\
\hline \multicolumn{2}{|r|}{ The environmental dimension as a whole. } & 3.02 & 0.67 & 60.4 & Medium & 5 \\
\hline
\end{tabular}

Particulars of Table No. (7) show the following:

1. The means of the sample participants' evaluations on the items of planning method dimension ranged between 3.60 and 3.90. Item (3) providing "The university applies the strategic management method to achieve the sustainable development", ranked first; and item (2) providing "The university has a conviction of the sustainable development importance", ranked last.

2. The means of the sample participants' evaluations on the items of development requirements dimension ranged between 3.44 and 3.91. Item (5) providing "The university provides the required human cadres to achieve the sustainable development", ranked first; and item (6) providing "The ministry provides the required infrastructure to achieve the sustainable development", ranked last.

3. The means of the sample participants' evaluations on the items of economic dimension ranged between 3.39 and 3.52. Item (8) providing "The university works on reducing the poverty and unemployment levels among the community members", ranked first; and item (7) providing "The university works on raising the economic growth level to improve the living level of the individuals", ranked last. 
4. The means of the sample participants' evaluations on the items of social dimension ranged between 3.09 and 3.53. Item (9) providing "The university works toward achieving the human development and building the knowledge labor of the community members", ranked first; and item (10) providing "The university seeks to increase and strengthening the role of the civil organizations in achieving the sustainable development", ranked last.

5. The means of the sample participants' evaluations on the items of environmental dimension ranged between 2.97 and 3.08. Item (11) providing "The university depends on employing the research results to address the environmental issues", ranked first; and item (13) providing "The university aims at achieving the balanced environmental development among all the colleges", ranked last.

\subsection{Results of the third question and their interpretation}

Is there a role at $(\alpha \geq 0.05)$ statistical significance level in achieving sustainable development as seen by the academic leaders in the University?

Table 8: Answers the question through the results of applying the multiple regression equation to study the effects of the dimensions of effective planning in response to achieving sustainable development as a whole.

\begin{tabular}{|c|c|c|c|c|c|c|c|c|}
\hline Dimension & B & $T$ & Sign. & $\mathbf{R}$ & $\mathbf{R 2}$ & Adjusted R Square & $\mathbf{F}$ & Sig \\
\hline Planning method & 0.21 & 5.47 & 0.00 & \multirow{5}{*}{0.70} & \multirow{5}{*}{0.49} & \multirow{5}{*}{ 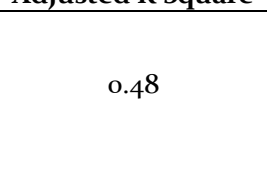 } & \multirow{5}{*}{89.04} & \multirow{5}{*}{0.00} \\
\hline Financial and human resources & 0.13 & 3.64 & 0.00 & & & & & \\
\hline Strategy & 0.19 & 4.47 & 0.00 & & & & & \\
\hline Participation and training & 0.25 & 5.73 & 0.00 & & & & & \\
\hline Infrastructure & 0.33 & 7.93 & 0.00 & & & & & \\
\hline
\end{tabular}

Table 8 shows the following:

1. There is a statistically significant effect at the level $(\alpha \geq 0.005)$ of the dimensions of effective planning in achieving sustainable development as a whole. The correlation coefficient (R) was (o.70), which is a statistically significant value.

It is also a function between the independent variable and the dependent variable

(o.49), a value that explains the ability of effective planning to affect sustainable development as a whole. In other words, effective planning (49\%) explains the change in achieving sustainable development. The value of the (F) test was (89.04) with statistical significance (o.oo), which is also a statistically significant value indicating the existence of a discrepancy in the ability of the independent variables to influence the dependent variable. According to the main premise in its proven form that provides "there is an important role at ( $\alpha \geq 0.005)$ significance level for effective planning in achieving sustainable development as seen by academic leaders". " is accepted.

2. There is a statistically significant effect at $(\alpha \leq 0.005)$ significance level of the effective planning dimensions separately on the sustainable development as a whole, as $(T, ß)$ are statistically significant.

The reason for that, as the researchers see, is that the interest in the strategic plans makes the university stronger in facing many of the changes imposed by the economic, social, cultural, and political facts. These changes caused many problems that should be thought of to address and solve in innovative ways, unlike the traditional ways, which will make the university more interested in effective planning and preparing strategic plans. This result could be further interpreted by that the university seeks success in its operations and activities to build a strategic and competitive center to it, and an efficient performance in the light of the environment it works in, which require the university to have a long term vision.

This result is in agreement with Ak-Zo'bi's study (2014) that showed a relationship between the 
strategic planning practice in Jordanian universities and human resources development. It is also in line with the study of Ahmad (2016) that showed a relationship between strategic planning and the performance efficiency in the developmental sector, as well as the study of Ali (2010), which showed an effect of the strategic planning and the economic and human development in Yemen.

\section{Recommendation}

Building on the study results, the researchers provided the following recommendations:

1. Circulating the idea of adopting effective planning in the university and the management of its colleges, is a method that assists in achieving its vision and mission.

2. Providing qualified human abilities and the required financial provisions to implement the strategic plans that aim at achieving sustainable development at a high level.

3. Spreading awareness on the concept, significance, and dimensions of sustainable development in the university.

4. The university should apply the strategic management method for the human, financial and natural resources, to achieve sustainable economic, social, and environmental development.

5. The university should invest the results of the scientific studies in this field to address the economic, social, and environmental issues and transform the knowledge into wealth.

\section{Conclusions}

The researchers concluded the following:

- In the light of this study, the university will be able to prepare graduate students and staff who understand the roles they play.

- The university will be able to conduct scientific and experimental research and conduct direct and indirect interviews to create a generation capable of facing future problems in a forwardlooking and reflective manner.

- The university will be able to continuously consolidate its relationship with the community and exert more effort to serve it.

- The focus will be on providing good university training that achieves compatibility between quantitative and qualitative outputs and the requirements of sustainable development, focusing on applied research and marketing it, and contributing to the development of the environment by opening doors for community institutions to benefit from the services of the university.

- Information signals on their weakness will be invested in universities and focus on improving competitiveness in the university, processing information and spreading knowledge to control the environment from two aspects: threats and opportunities.

- It is expected to formulate a future strategic plan with regard to university education, in order to provide high-quality, distinguished and competitive educational outputs that meet the requirements and needs of the changing labor market.

- It is expected to develop a comprehensive and integrated educational system for education at the university, taking into account its human and material capabilities available to develop the performance of its university system.

- It is expected to formulate procedural goals and use them as a model upon which to achieve the requirements of sustainable development at the university

- The university is expected to develop sustainable development in all its educational, social, cultural, administrative, economic, health and environmental fields in order to develop for the better.

- Focusing on making sustainable development an effective strategic goal for the university, as it is an urgent social demand, and therefore it is a measure of the level of progress and development at both levels (institutional and societal). 


\section{References}

Abdel-Mawla, D. \& Al-Sayyid, I. (2017). Strategic Prediction.Egypt. University Education House.

Al-Ali, A. (2017). Strategic Planning in Achieving the Comprehensive Development in Al al-Bayt University. AkManara Magazine, Al-al-Bayt University, Vol. 16, No. 23, pp45-76.

Al-Ghzawi, F. \& Al-Sharafat, A. (2014). "Reality of the Sustainable Development in the Jordanian Badia- Field Study, Northeast Badia Area- Arab Universities Union Magazine, Vol. 11, No. 3, pp.27-24.

Al-Kurd, D. (2018). The Anticipated Role of the Palestinian Universities in Strengthening the Sustainable Development. A paper presented to the conference on "The sustainable development in the light of a changing environment." Faculty of Economics and Social Sciences- An-Najah National University.

Al-Qahtani, M. (2014). "Use of the Strategic Planning Models in Preparing a Strategic Plan." Presented to the Faculty of Education, King Khalid University. The Specialized International Educational Magazine, Vol. 3 No.1, Saudi Arabia.

Al-Qeeli, A. (2017). Strategic Planning, an Important Factor in the Comprehensive Development in the Syrian Educational Institutions. Educational and Human Science Magazine, Damascus University, Vol. 22, No. 3, pp.123-152.

Al-Zo'bi, E. (2014). Practice Degree of the Strategic Planning in the Jordanian Universities and its Relationship with the Human Resources Development. Ph.D. Dissertation, Al-Yarmouk University, Jordan.

Assaf, M. (2015). Role of Enablement in Achieving Sustainable Development in the Palestinian Universities. Jarash Journal for research and studies. Jordan, Vol. 16, No. 1, pp.365-392.

Bin Omar, H. (2015). "The Social Dimensions in the Sustainable Development in Tunis: Labor, Unemployment, and Poverty as Measurement Indicators." Arab Future Magazine, Vol. 38, No. 442, Tunis.

D'ais, L. (2020). Role of the Universities in the Development and Providing the Labor Market with Young Capable People. Literature, Humane and Social Sciences Magazine. Vol. 2, No. 7, pp 45-71

Ja'afar, Y. (2017). Effect of the Strategic Planning in the Educational Institutions, Applied Study: Public institutions in Jerusalem suburbs. Al-Aqsa University (Journal Human Science Series), Vol. 21, No. 1, pp.293-324.

Mohammad, A. A. (2015). Role of the Universities in Achieving the Sustainable Development in Sudan. Case Study, Sudan University of Science and Technology. Jarash Journal for Research and Studies, Vol. 16, No. 1, pp.315338, Jordan.

Mraizeeq, A. (2011). Role of the Higher Education and Scientific Research in Achieving Sustainable Socioeconomic Development. Conference on "Future vision to raise the scientific research in the Arab World". Arab Organization for Administrative Development, Jordan, pp. 345-321.

Nasr, Y. M. (2015). Role of the University Education in Achieving Sustainable Development as seen by the Students. Jarash Journal for Research and Studies, Vol. 16, No.1, pp.241-268.

Pollard, S. (2006), "Crises, Scenarios and the Strategic Management Process", Management Decision, Vol44, No.6, pp. 91-118

Saleh, A. (2-13). Strategic Planning in our Higher Education Institutions. Field study of the trends of the Omani private universities' directors. Dananeer Magazine, Vol. 4, No. 12, pp.132-165

Saleh, R. (2011). Effect of the Strategic Planning in the Organizational Change- Case Study in the Public Company of South Oil. Basra.) Basra Studies Magazine, No. 11, Iraq.

Sha'ath, N. M. (2015). "Position of Planning as an Element of the Administrative Process in the Main Islamic Thought Resources." Al-Naser University Journal. Palestine, Vol. (1), No. 2, pp.322-367.

Shweideh, M. (2015). Practice Degree of the Education Department of UNRWA Gaza of the Electronic Management and its Relationship with the Strategic Planning Processes. Ph.D. Dissertation. Islamic University, Palestine.

Smith, M. (2013): "Strategic Planning in Higher Education: " and Crisis Management,9 (4) pp. 99-108. 